\title{
Aggressiveness of Mycosphaerella graminicola Isolates from Susceptible and Partially Resistant Wheat Cultivars
}

\author{
Christina Cowger and Christopher C. Mundt
}

Department of Botany and Plant Pathology, 2082 Cordley Hall, Oregon State University, Corvallis 97331. Accepted for publication 28 February 2002.

\begin{abstract}
Cowger, C., and Mundt, C. C. 2002. Aggressiveness of Mycosphaerella graminicola isolates from susceptible and partially resistant wheat cultivars. Phytopathology 92:624-630.

The selective effect of quantitative host resistance on pathogen aggressiveness is poorly understood. Because two previous experiments with a small number of bread wheat cultivars and isolates of Mycosphaerella graminicola had indicated that more susceptible hosts selected for more aggressive isolates, we conducted a larger experiment to test that hypothesis. In each of 2 years, six cultivars differing in their levels of partial resis-

tive impact of a cultivar on aggressiveness was measured as the difference in aggressiveness between early and late isolates from that cultivar. Regression of those differences on disease severity in the field yielded significance values of 0.0531 and 0.0037 for the 2 years, with moderately resistant cultivars selecting for more aggressive isolates. In a related experiment, the protectant fungicide chlorothalonil was applied to plots of two susceptible cultivars to retard epidemic development. When tested in the greenhouse, isolates of $M$. graminicola from those plots were significantly more aggressive than isolates from the same cultivars unprotected by fungicide.
\end{abstract} tance were planted in field plots, and isolates were collected from each cultivar early and late in the growing season. The isolates were inoculated as populations bulked by cultivar of origin, field replicate, and collection date on seedlings of the same six cultivars in the greenhouse. The selec-
Additional keywords: pathogenicity, Septoria tritici blotch, Triticum aestivum, virulence.
In this paper, we employ Vanderplank's (23) definitions of pathogenicity as the sum of a pathogen's disease-causing abilities, including both virulence (specific disease-causing abilities) and aggressiveness (nonspecific disease-causing abilities). Host selective effects on pathogenicity are an important aspect of host-pathogen interactions. Research on a host's selective impact on virulence is relatively common, with efforts more on qualitative than on quantitative interaction. Very few reports can be found of host selective impacts on aggressiveness, despite the large number of quantitatively varying pathosystems.

The data that are available tend to support the conclusion that resistant hosts select for more aggressive pathogens than do susceptible hosts. In one example (22), potato cyst nematodes (Globodera pallida) reared for several generations on resistant potato cultivars exhibited an increased reproductive rate, whereas those raised on susceptible potato cultivars did not. Pink et al. (19) suggested that multiplication of Lettuce mosaic virus in lettuce (Lactuca sativa) cultivars with relatively high levels of partial resistance may have contributed to the emergence of new, more aggressive viral pathotypes.

A report from our laboratory (1), subsequently cited by others $(2,3,5,6,14-18,20,21)$, suggested that more susceptible cultivars of winter wheat (Triticum aestivum) select for more aggressive isolates of Mycosphaerella graminicola. The evidence came from two greenhouse experiments in which wheat seedlings were challenged with isolates previously obtained from the same cultivars grown in field plots. Four cultivars were used in the first study and two cultivars in the second study. Similar results, though smaller in magnitude, had been obtained with Xanthomonas oryzae pv. oryzae on rice (C. C. Mundt, unpublished data). When

Corresponding author: C. Cowger; E-mail address: cowgerc@bcc.orst.edu

Publication no. P-2002-0416-03R

(c) 2002 The American Phytopathological Society
80 isolates of the rice pathogen collected from each of two cultivars in replicated field experiments at each of two locations were tested on the same cultivars in the greenhouse, the isolates from the susceptible cultivar caused significantly longer lesions than those from the moderately resistant cultivar.

Although evidence that susceptible cultivars select for greater aggressiveness was surprising, it was hypothesized $(1,17)$ that such an effect might be explained by a greater variance in the pathogen's reproductive rate (lesions produced per lesion per day) on the susceptible cultivars. Since gain due to selection is directly proportional to genetic variance, one could thus expect a more rapid increase in aggressiveness on the susceptible cultivars. Alternatively, more aggressive isolates could be selected directly by some cultivar phenotypes, perhaps pleiotropically by the characters conferring susceptibility, and not as a result of the more intense epidemics occurring on those cultivars.

M. graminicola causes the foliar disease Septoria tritici blotch in wheat. This pathosystem is useful for investigation of host selective effects on aggressiveness. In the Willamette Valley of Oregon, the site of our research, the pathogen population possesses high levels of genetic variability (26) and thus the basis for rapid adaptation. Disease severity varies quantitatively, and most studies of resistance to $M$. graminicola in bread wheat have found that additive effects predominate $(4,9,10)$. Moreover, host resistance is the method of choice for controlling this economically increasingly important pathogen $(5,24)$, and it is therefore desirable to understand how the deployment of partial resistance affects pathogenicity.

The present research tested two hypotheses. First, we tested the hypothesis that host susceptibility was associated with greater aggressiveness among isolates. To do so, we used a larger number of cultivars and isolates than did Ahmed et al. (1), and chose cultivars that were not closely related. Our second hypothesis was that, on susceptible cultivars, a higher pathogen reproductive rate was by itself sufficient to explain more rapid selection for aggres- 
siveness. This hypothesis was tested by applying lowered rates of a protectant fungicide to susceptible cultivars to reduce pathogen reproduction.

\section{MATERIALS AND METHODS}

Overview. In each of two winter wheat seasons (1997-98 and 1998-99), field plots were planted in a randomized, complete block design with four replicates. The treatments were six soft white winter wheat cultivars (Table 1) and four additional treatments in which two of the susceptible cultivars were sprayed with a protectant fungicide to artificially reduce the rate of epidemic development. Isolates collected each year were used the subsequent winters in greenhouse experiments to measure aggressiveness.

Field experiments. Plot establishment. Field plots were established at the Oregon State University Botany and Plant Pathology Field Laboratory in Corvallis. Each of the four plots of each treatment occupied two adjacent planting units $(1.5 \times 6.1 \mathrm{~m})$. Equal-sized plots of wheat and barley were alternated in a checkerboard pattern so that the barley provided a buffer between the wheat plots.

Three of the cultivars (Stephens, Madsen, and MacVicar) were commonly grown in western Oregon, where the experiment took place. The other three cultivars, not commonly grown in this region, were chosen to provide a balance between moderately resistant and susceptible cultivars. The moderately resistant cultivars had expressed approximately one-half of the level of disease found on the susceptible cultivars in western Oregon (J. A. DiLeone and S. M. Coakley, unpublished data). Heights of the six cultivars were uncorrelated with susceptibility to $M$. graminicola.

Plots were planted on 20 October 1997 and 7 October 1998. Fertilization, planting, and weed control were all conducted according to standard commercial practices in the area.

Fungicide applications. Reduction in the reproductive rate of the pathogen was accomplished by applying the nonsystemic protectant fungicide chlorothalonil (Bravo 720, $720 \mathrm{~g}$ of chlorothalonil per liter, $54 \%$ a.i.) to plots of two susceptible cultivars, Stephens and W-301. Chlorothalonil is a broad-spectrum, multisite fungicide that was chosen because it was not expected to exert specific selective influences on pathogen populations. The concentration was $1.8 \mathrm{ml}$ of Bravo per liter of water, about $40 \%$ of manufacturer's recommended strength, with the surfactant Triton $\mathrm{B}$ added at the rate of $0.176 \mathrm{ml} / \mathrm{liter}$. The rate of application was 0.84 liter per plot (468 liters/ha). In the first year, applications were made seven times at intervals of 2.5 to 5 weeks, depending on the growth rate of the wheat, from 10 December to 22 May. In the second year of the experiment, in order to allow formation of more lesions from which to obtain isolates, fungicide was applied only five times at approximately 3-week intervals between late January and late April. A lower dosage, $0.88 \mathrm{ml} /$ liter, was applied to plots of cvs. Stephens and W-301 in 1999.

Disease measurements. Visual assessments of percent diseased leaf area were conducted by two assessors for each plot on a whole-canopy basis on 15 June 1998 and 17 June 1999.

Isolate sampling. Leaves infected with $M$. graminicola were collected from the field plots on 19 February 1998 and 25 February 1999 , before significant secondary infection had taken place, and on 12 June 1998 and 24 June 1999, after there had been ample opportunity for host treatments to exert selective influences on the pathogen populations. These collection times will be referred to as early and late. Leaves were collected as follows: along a diagonal transect across each 12-row plot, the flag (1998) or F-1 (1999) leaf was collected from each of two adjacent plants chosen at random in each of the innermost 10 rows of the plot. F-1 leaves were collected in 1999 because, due to the lighter epidemic that year, flag leaves on the more resistant cultivars had too few lesions to assure that isolates could be obtained. Leaves were bagged separately by row.

In the laboratory, monopycnidial isolates of $M$. graminicola were obtained from the leaves separately by collection date, replicate, cultivar of origin, and row. Isolations were made by placing leaf segments bearing lesions in petri dishes lined with moistened filter paper overnight, and then transferring cirrhi individually with a needle to plates of yeast-malt agar amended with $50 \mathrm{mg} / \mathrm{liter}$ of streptomycin. The isolates were stored at $4{ }^{\circ} \mathrm{C}$ and transferred to fresh medium every 3 to 5 months.

Greenhouse trials. In 1999 and 2000, pathogen populations collected in the field during the previous growing season were evaluated in the greenhouse in two experiments addressing the first and second hypotheses, respectively.

Tester plants. Tester cultivars used to address the first hypothesis, that susceptible cultivars select for more aggressive isolates, were the same as the six cultivars from which the isolates were obtained (Table 1). Testers for the second hypothesis, that a faster rate of pathogen reproduction accounts for more aggressive isolates on susceptible cultivars, were the two cultivars subjected to the rate-reducing fungicide treatment in the field (cvs. Stephens and W-301) and moderately resistant cv. Madsen.

The experimental unit was a pot of seedlings. In the first year, plants were raised in $10-\mathrm{cm}$ plastic pots filled with a 1:1:1:2 mixture of peat/sand/loam/no. 8 pumice amended with Osmocote 18-6-12 extended time-release fertilizer (Scott-Sierra Horticultural Products Co., Marysville, $\mathrm{OH}$ ) at a rate of approximately $1 \mathrm{~g}$ per pot at seeding. Approximately 13 seeds of a cultivar were sown in each pot, and seedlings were thinned to 10 plants per pot at about 18 days after planting. The plants were grown under sodium halide lighting to extend the day length to $16 \mathrm{~h}$, and watered as needed. To control powdery mildew, plants were treated as necessary with $50 \mathrm{ml}$ of a soil drench of ethirimol $(0.11 \mathrm{~g}$ a.i./liter $)$, which has no influence on the development of $M$. graminicola. The greenhouse temperature was maintained at 20 to $25^{\circ} \mathrm{C}$.

During the second greenhouse season, because of problems in the previous year with emergence, growth, and nondisease-related necrosis, plants were raised in Black Gold all-organic potting soil (Black Gold, Inc., Hubbard, OR) amended with approximately $2.5 \mathrm{~g}$ of Osmocote per pot. Pots were fertilized weekly with $50 \mathrm{ml}$ of Peters water-soluble 20-20-20 fertilizer (United Industries Corp., St. Louis) at the rate of $3.8 \mathrm{~g}$ per liter of water. Watering, temperature, and lighting were the same as in the first year.

Inoculum preparation and inoculation. For greenhouse tests of 1998 isolates, each experiment had four replicates in time, with each replicate testing a pathogen population from a different block in the field experiment. Isolates were increased individually for 4 days on fresh yeast-malt agar. Isolate populations were created

TABLE 1. Field disease severity of winter bread wheat cultivars used in field and greenhouse experiments to test selective effects of host resistance on aggressiveness of Mycosphaerella graminicola populations

\begin{tabular}{llll}
\hline & & \multicolumn{2}{c}{ Disease severity } \\
\cline { 3 - 4 } Treatment cultivar & Accession No. & 1998 & 1999 \\
\hline Lewjain & CI 17909 & 43.3 & 30.0 \\
Cashup & PVP 8500178 & 61.0 & 43.3 \\
Madsen & PI 511673 & 71.3 & 51.8 \\
W-301 & PI 559718 & 77.5 & 57.8 \\
MacVicar & PI 552427 & 73.5 & 66.0 \\
Stephens & CI 017596 & 79.0 & 67.0 \\
Stephens $(1.8 \mathrm{ml})^{\mathrm{z}}$ & CI 017596 & 25.8 & 41.8 \\
Stephens $(0.88 \mathrm{ml})^{\mathrm{z}}$ & CI 017596 & $\ldots$ & 43.8 \\
W-301 $(1.8 \mathrm{ml})^{\mathrm{z}}$ & PI 559718 & 31.3 & 41.4 \\
W-301 $(0.88 \mathrm{ml})^{\mathrm{z}}$ & PI 559718 & $\ldots$ & 44.0 \\
\hline
\end{tabular}

y Mean percent diseased canopy area of four field replicates on 15 June 1998 and 17 June 1999.

${ }^{z}$ Plots sprayed with the protectant fungicide chlorothalonil (milliliter of Bravo 720 per liter of water) to reduce the rate of pathogen reproduction. 
by mixing spores of each isolate from a given field plot in an equiproportional suspension that was adjusted to a concentration of $10^{5}$ spores per $\mathrm{ml}$ just prior to inoculation.

In the first experiment, which measured aggressiveness of early and late isolates, the target number of isolates in a population was 10 , corresponding to the 10 rows in the plot from which isolates were sampled. In some cases, due to poor isolate growth or contamination, the actual number of isolates in an equiproportional mixture was less than 10 . However, in only 5 of the 48 treatments comprising the four replicates did the number of isolates in a population fall below eight (four, five, six, six, and seven isolates), and all five involved different cultivars of origin.

When plants were 21 days old, a group of six pots comprising one pot of each cultivar was inoculated with $50 \mathrm{ml}$ of each isolate population plus 1 drop of surfactant, which was sufficient to inoculate the plants to run off. Inoculation was performed with spray bottles and a turntable. After inoculation, the plants were kept in a greenhouse mist chamber for $96 \mathrm{~h}$. Noninoculated control plants were sprayed with water and surfactant only, but otherwise treated in the same manner as inoculated plants in order to control for contamination among pots.

In the second experiment (effect of rate reduction), five isolates from each plot were bulked, due to the shortage of isolates available from some of the sprayed plots. For each isolate population, $25 \mathrm{ml}$ was applied to the three pots of the tester cultivars.

In greenhouse tests of 1999 isolates, isolate production for the early/late experiment was the same as before, except that 1 of the 48 bulked-isolate treatments had to be omitted due to poor growth and contamination, and 11 other treatments contained fewer than eight isolates (one had four, four had five, three had six, and three had seven). For the rate-reduction experiment, five isolates were available from 16 of the 24 plots; four isolates from three; three from three; two from one; and one treatment (cv. W-301 highspray replicate two) had to be omitted due to lack of isolates. As a

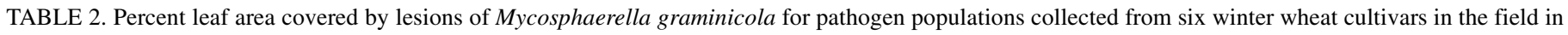
1998 and 1999 and subsequently tested on the same cultivars in the greenhouse

\begin{tabular}{|c|c|c|c|c|c|c|c|c|c|}
\hline \multicolumn{3}{|c|}{ Source of isolate ${ }^{w}$} & \multicolumn{7}{|c|}{ Tester cultivar ${ }^{\mathrm{x}}$} \\
\hline Collection time & Resistance & Cultivar & Cashup & Madsen & Stephens & W-301 & MacVicar & Lewjain & Mean ${ }^{y}$ \\
\hline \multicolumn{10}{|l|}{1998} \\
\hline Early & $\mathrm{S}$ & MacVicar & 16.6 & 22.2 & 20.0 & 29.0 & 31.7 & 28.7 & 24.7 \\
\hline Early & $\mathrm{S}$ & Stephens & 16.8 & 35.0 & 22.3 & 21.8 & 23.9 & 23.8 & 23.9 \\
\hline Early & $\mathrm{S}$ & W-301 & 13.6 & 20.0 & 24.8 & 14.2 & 29.0 & 23.5 & 20.8 \\
\hline Mean of early $S$ & & & 15.7 & 25.7 & 22.3 & 20.7 & 28.8 & 25.0 & $\underline{23.0 \mathrm{a}}$ \\
\hline Early & MR & Cashup & 19.5 & 27.6 & 24.1 & 21.5 & 26.7 & 23.8 & 23.9 \\
\hline Early & MR & Lewjain & 18.5 & 18.8 & 20.5 & 21.6 & 30.3 & 24.5 & 22.4 \\
\hline Early & MR & Madsen & 18.9 & 17.8 & 28.9 & 17.4 & 29.9 & 33.2 & 24.3 \\
\hline Mean of early MR & & & 19.0 & 21.4 & 24.2 & 20.1 & 29.0 & 27.2 & $23.5 \mathrm{a}$ \\
\hline Late & $\mathrm{S}$ & MacVicar & 13.7 & 19.0 & 16.4 & 12.0 & 28.8 & 25.3 & 19.2 \\
\hline Late & $\mathrm{S}$ & Stephens & 16.5 & 18.8 & 16.5 & 18.1 & 19.8 & 30.0 & 20.0 \\
\hline Late & $\mathrm{S}$ & W-301 & 8.4 & 15.8 & 14.6 & 16.2 & 17.4 & 18.5 & 15.1 \\
\hline Mean of late $S$ & & & 12.9 & 17.9 & 16.0 & 15.4 & 22.0 & 24.6 & $18.1 \mathrm{~b}$ \\
\hline Late & MR & Cashup & 18.4 & 23.0 & 15.5 & 17.9 & 15.2 & 28.0 & 19.6 \\
\hline Late & MR & Lewjain & 13.1 & 24.3 & 12.7 & 16.2 & 28.6 & 22.6 & 19.6 \\
\hline Late & MR & Madsen & 14.7 & 20.4 & 15.6 & 15.9 & 19.1 & 25.8 & 18.6 \\
\hline Mean of late MR & & & 15.4 & 22.6 & 14.6 & 16.9 & 20.2 & 25.5 & $19.2 \mathrm{~b}$ \\
\hline Mean of all early & & & 17.3 & 23.5 & 23.4 & 20.9 & 28.6 & 26.3 & $23.3 \mathrm{a}$ \\
\hline Mean of all late & & & 14.1 & 20.2 & 15.2 & 16.1 & 21.5 & 25.0 & $18.7 \mathrm{~b}$ \\
\hline Mean of $1998^{z}$ & & & $15.7 \mathrm{a}$ & $21.9 \mathrm{bc}$ & $19.3 \mathrm{ab}$ & $18.3 \mathrm{ab}$ & $25.0 \mathrm{~cd}$ & $25.6 \mathrm{~d}$ & 21.7 \\
\hline \multicolumn{10}{|l|}{1999} \\
\hline Early & $\mathrm{S}$ & MacVicar & 21.7 & 4.3 & 15.4 & 25.0 & 11.1 & 15.8 & 15.5 \\
\hline Early & $\mathrm{S}$ & Stephens & 13.0 & 8.3 & 13.1 & 28.6 & 18.8 & 17.7 & 16.6 \\
\hline Early & $\mathrm{S}$ & W-301 & 21.1 & 8.9 & 25.6 & 16.5 & 23.7 & 26.3 & 20.4 \\
\hline Mean of early S & & & 18.3 & 7.4 & 18.3 & 23.2 & 18.5 & 20.3 & $\underline{17.7 \mathrm{a}}$ \\
\hline Early & MR & Cashup & 20.0 & 11.5 & 16.1 & 24.4 & 20.3 & 25.8 & 19.7 \\
\hline Early & MR & Lewjain & 15.0 & 6.7 & 16.3 & 13.3 & 24.1 & 27.3 & 17.1 \\
\hline Early & MR & Madsen & 14.6 & 6.6 & 17.2 & 7.9 & 14.9 & 23.9 & 14.2 \\
\hline Mean of early MR & & & 16.5 & 8.3 & 16.5 & 15.2 & 19.8 & 25.7 & $17.0 \mathrm{a}$ \\
\hline Late & $\mathrm{S}$ & MacVicar & 6.3 & 5.1 & 10.2 & 17.6 & 18.9 & 26.4 & 14.1 \\
\hline Late & $\mathrm{S}$ & Stephens & 12.7 & 7.0 & 17.1 & 20.1 & 15.9 & 12.2 & 14.2 \\
\hline Late & $\mathrm{S}$ & W-301 & 25.1 & 7.2 & 20.4 & 18.8 & 15.9 & 14.2 & 16.9 \\
\hline Mean of late $S$ & & & 14.7 & 6.5 & 15.9 & 18.8 & 16.9 & 17.6 & $\underline{15.1 \mathrm{a}}$ \\
\hline Late & MR & Cashup & 25.6 & 10.8 & 21.4 & 26.9 & 16.9 & 31.4 & 22.2 \\
\hline Late & MR & Lewjain & 24.3 & 6.3 & 22.8 & 16.2 & 27.8 & 35.1 & 22.1 \\
\hline Late & MR & Madsen & 11.7 & 6.2 & 8.4 & 18.1 & 24.0 & 12.9 & 13.6 \\
\hline Mean of late MR & & & 20.5 & 7.8 & 17.6 & 20.4 & 22.9 & 26.4 & $\underline{19.3 \mathrm{a}}$ \\
\hline Mean of all early & & & 17.6 & 7.7 & 17.3 & 19.3 & 18.8 & 22.8 & $17.3 \mathrm{a}$ \\
\hline Mean of all late & & & 17.6 & 7.1 & 16.7 & 19.6 & 19.9 & 22.0 & $17.2 \mathrm{a}$ \\
\hline Mean of all $1999^{z}$ & & & $17.5 \mathrm{~b}$ & $7.5 \mathrm{a}$ & $17.1 \mathrm{~b}$ & $19.4 \mathrm{~b}$ & $19.5 \mathrm{~b}$ & $22.5 b$ & 17.3 \\
\hline
\end{tabular}

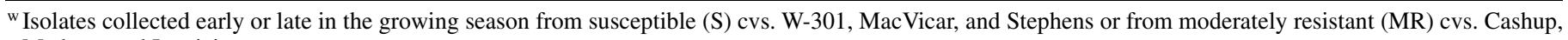
Madsen, and Lewjain.

$\mathrm{x}$ Values are least-squares means of three trials for 1998 and four trials for 1999, each using isolates from a different field replicate.

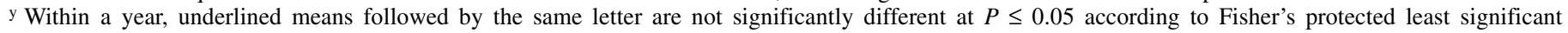

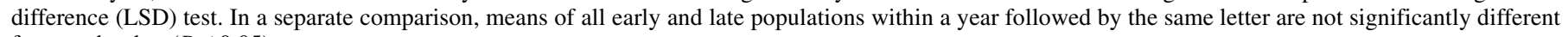
from each other $(P \leq 0.05)$.

${ }^{z}$ Within a row, means followed by the same letter are not significantly different at $P \leq 0.05$ according to Fisher's protected LSD test. 
result of tests to optimize soil fertility and disease severity, inoculum concentrations were increased to $10^{6}$ spores per $\mathrm{ml}$.

Disease assessment. In order to assess disease levels of all plants in a given experiment in the same day, two workers conducted the assessments, each assessing half of the plants in each pot. The percentage of the second leaf from the base of the plant covered by Septoria tritici blotch lesions and lesion-associated necrotic area was estimated visually for each plant in each pot at 21 days after inoculation. The exception was the early/late experiment with 1999 isolates, in which the third leaf from the base was read because of high levels of senescence on the second leaf.

Statistical methods. For each cultivar as an isolate source, the mean disease severity caused by early isolates across all testers $\left(A_{E}\right)$ was subtracted from the mean disease severity caused by late isolates across all testers $\left(A_{L}\right)$. These early/late differences in aggressiveness, $A_{L}-A_{E}$, were regressed on disease severity as assessed in the field for each cultivar.

Data were subjected to analysis of variance using the SAS PROC MIXED procedure (SAS Institute, Cary, NC), which takes missing data into account (11 pots among the four replicates were unusable the first year, and no early 'MacVicar' isolates were available in replicate three of the second year). Because disease severity on the water controls in the greenhouse studies was negligible, these values were excluded from the analysis in order to avoid underestimating the mean square for error. Data were $\log _{\mathrm{e}^{-}}$ transformed to improve homogeneity of variance. Fisher's protected least significant difference test was used to separate means of testers and of isolate populations derived from moderately resistant and susceptible cultivars by collection date. Linear contrasts were used to test the differences in aggressiveness of populations collected at a particular date from cultivars with a particular resistance level (moderately resistant or susceptible).

\section{RESULTS}

Unlike Ahmed et al. (1), we found no evidence that susceptible cultivars selected for more aggressive populations of M. graminicola than moderately resistant cultivars (Table 2; Fig. 1). On the contrary, it is apparent from the regression of early/late aggressiveness differences $\left(A_{L}-A_{E}\right)$ on disease severity (Fig. 1) that moderately resistant cultivars selected for smaller declines or larger gains in aggressiveness than susceptible cultivars, with $P$ values of 0.0531 and 0.0037 in 1998 and 1999, respectively.
There was no significant difference in aggressiveness between isolates from moderately resistant and susceptible cultivars at either collection date in either year (Table 2). No significant interaction of cultivar as an isolate source and tester occurred in either year (Tables 2 and 3), and the interaction of isolate source, tester, and collection date was nonsignificant in both years (Table 3). Disease severity varied significantly among testers in both years. There were significant differences in aggressiveness of populations from different isolate sources across collection dates in 1999, but not in 1998 (Table 3). Late isolate populations were significantly less aggressive than early populations in 1998, but there was no difference in aggressiveness between populations collected early and late in 1999. There was modest evidence that fungal populations were selected for greater pathogenicity on their hosts

TABLE 3. Analysis of variance of pathogenicity of Mycosphaerella graminicola isolate populations derived from three moderately resistant and three susceptible wheat cultivars in the field in 1998 and 1999 and tested on the same cultivars as seedlings in the greenhouse

\begin{tabular}{lrrr}
\hline Source of variation & df & $F$ value & $P$ value \\
\hline 1998 & & & \\
Isolate source $(\mathrm{I})^{\mathrm{x}}$ & 4 & 0.67 & 0.6283 \\
Tester $(\mathrm{T})^{\mathrm{x}}$ & 5 & 4.52 & 0.0103 \\
$\mathrm{I} \times \mathrm{T}$ & 20 & 0.78 & 0.7404 \\
Adaptation to host $^{\mathrm{y}}$ & 1 & 1.70 & 0.0901 \\
Collection date $(\mathrm{C})^{\mathrm{z}}$ & 1 & 10.25 & 0.0493 \\
$\mathrm{I} \times \mathrm{C}$ & 5 & 0.78 & 0.5637 \\
$\mathrm{I} \times \mathrm{T} \times \mathrm{C}$ & 25 & 0.59 & 0.9413 \\
1999 & & & \\
$\mathrm{I}^{\mathrm{x}}$ & 4 & 3.73 & 0.0357 \\
$\mathrm{~T}^{\mathrm{x}}$ & 5 & 10.45 & 0.0002 \\
$\mathrm{I} \times \mathrm{T}$ & 20 & 0.58 & 0.9267 \\
Adaptation to host & & & \\
$\mathrm{C}^{\mathrm{z}}$ & 1 & 0.30 & 0.7627 \\
$\mathrm{I} \times \mathrm{C}$ & 1 & 0.69 & 0.4718 \\
$\mathrm{I} \times \mathrm{T} \times \mathrm{C}$ & 5 & 0.09 & 0.9842 \\
& 25 & 0.38 & 0.9967 \\
\hline
\end{tabular}

${ }^{\mathrm{x}}$ Serving as isolate sources and testers were moderately resistant cvs. Cashup, Lewjain, and Madsen; and susceptible cvs. MacVicar, Stephens, and W-301.

${ }^{y}$ Linear contrast within $\mathrm{I} \times \mathrm{T}$ interaction to compare pathogenicity of late isolate populations on their cultivars of origin to their pathogenicity on other tester cultivars.

${ }^{\mathrm{z}}$ Isolates were collected either early (19 February 1998 and 25 February 1999) or late (12 June 1998 and 24 June 1999) in each growing season.

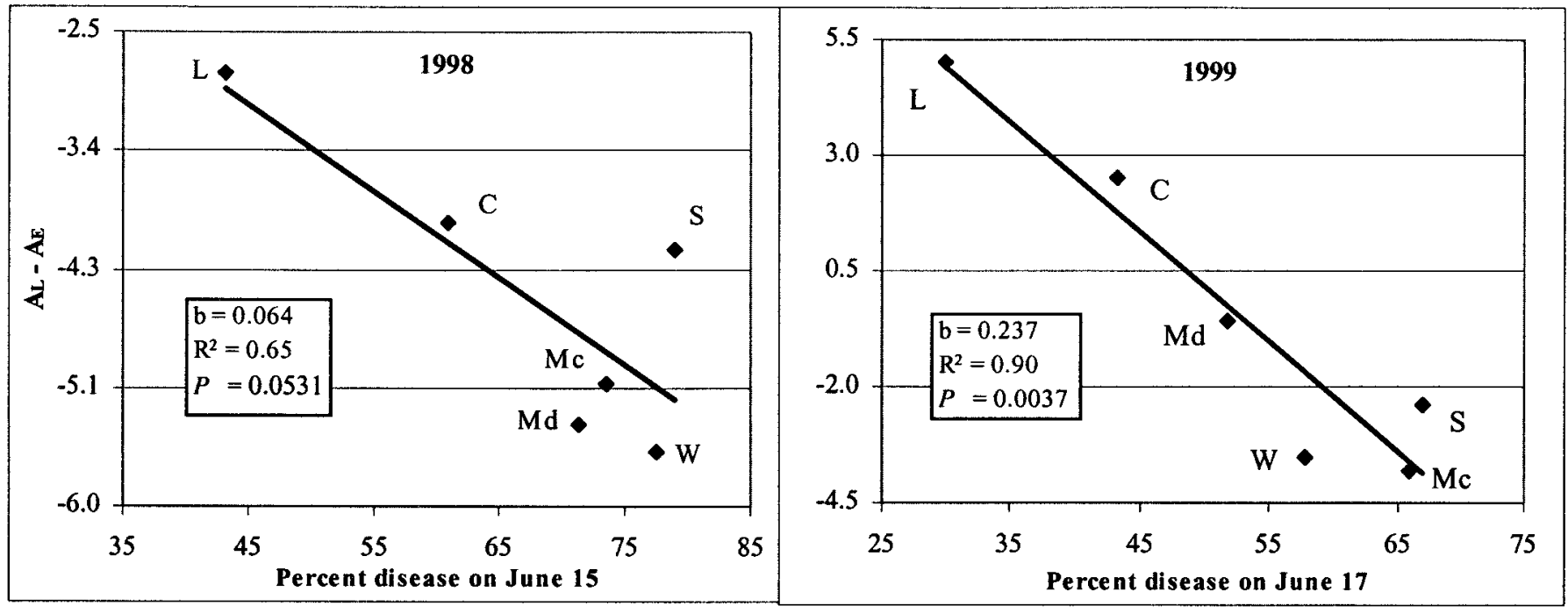

Fig. 1. Regression of $A_{L}-A_{E}$ (late aggressiveness - early aggressiveness) of Mycosphaerella graminicola as measured in the greenhouse on field disease severity for 2 years. Moderately resistant winter wheat cvs. Cashup (C), Lewjain (L), and Madsen (Md); and susceptible cvs. MacVicar (Mc), Stephens (S), and W-301 (W). 
of origin in 1998 (linear contrast, $P=0.0901$ ), but no such evidence in 1999.

Isolate populations from the fungicide-sprayed plots were significantly more aggressive than populations from unsprayed plots of the same cultivars in both years (Table 4). In 1999, both fungicide dosages selected for more aggressive populations, although aggressiveness was not statistically different between the two dosages. For 1998 populations, there was no significant interaction between the cultivar from which populations originated (cv. Stephens or cv. W-301) and the spray level $(P=0.1872)$. However, for 1999 populations there was some indication of such an interaction $(P=0.0907)$, with increased fungicide dosages associated more strongly with increased pathogenicity of isolates from cv. Stephens than from cv. W-301.

\section{DISCUSSION}

These experiments were undertaken to confirm unexpected evidence obtained by our research group that susceptible cultivars selected for more aggressive isolates (1). As it turned out, we obtained the opposite result with a larger set of cultivars and isolate populations that were specifically chosen to test this hypothesis.

Our finding is consistent with the few other available reports on selective impact of host resistance level on aggressiveness in quantitatively varying pathosystems $(19,22)$. It is not surprising that, in these systems, more resistant hosts should select for more aggressive isolates. If partial resistance and aggressiveness are nonspecific and are conferred additively by several genes, fungal individuals selected by a resistant host would likely possess one or more traits conferring an advantage on all host genotypes. Indeed, the model of Gandon and Michalakis (8) predicts that increasing levels of quantitative host resistance will select for increasing levels of damage caused by a parasite to the host, whereas qualitative host resistance will not exercise a similar selective effect.

TABLE 4. Percent leaf area covered by lesions of Mycosphaerella graminicola for pathogen populations collected in 1998 and 1999 from two winter wheat cultivars treated with different levels of a protectant fungicide in the field and tested on the same cultivars in the greenhouse

\begin{tabular}{lllll}
\hline & \multicolumn{4}{c}{ Tester cultivar } \\
\cline { 2 - 5 } Isolate sourcew $^{\mathrm{x}}$ & $\mathrm{W}-301$ & Stephens & Madsen & Mean $^{\mathrm{y}}$ \\
\hline 1998 & & & & \\
$\quad 0.0 \mathrm{ml}$ of chlorothalonil & 10.0 & 11.1 & 14.7 & $\underline{11.9 \mathrm{a}}$ \\
$1.8 \mathrm{ml}$ of chlorothalonil & 15.9 & 17.6 & 13.7 & $\underline{15.7 \mathrm{~b}}$ \\
Mean & $12.9 \mathrm{a}$ & $14.3 \mathrm{a}$ & $14.2 \mathrm{a}$ & 13.8 \\
'W-301' & 12.8 & 15.8 & 11.5 & $13.4 \mathrm{a}$ \\
'Stephens' & 13.0 & 12.8 & 16.8 & $14.2 \mathrm{a}$ \\
& & & & \\
1999 & 18.2 & 6.8 & 4.2 & $9.7 \mathrm{a}$ \\
$0.0 \mathrm{ml}$ of chlorothalonil & 26.4 & 14.9 & 6.2 & $\underline{15.9 \mathrm{~b}}$ \\
$0.88 \mathrm{ml}$ of chlorothalonil & 31.4 & 13.0 & 7.8 & $\underline{17.4 \mathrm{~b}}$ \\
$1.8 \mathrm{ml}$ of chlorothalonil & $25.2 \mathrm{a}$ & $11.7 \mathrm{~b}$ & $6.1 \mathrm{~b}$ & 14.3 \\
Mean & & & & \\
'W-301' & 24.8 & 11.2 & 4.9 & $13.6 \mathrm{a}$ \\
'Stephens' & 25.7 & 12.1 & 7.3 & $15.0 \mathrm{a}$ \\
\hline
\end{tabular}

${ }^{\mathrm{w}}$ Cultivars were treated with different levels of protectant fungicide at milliliters of Bravo 720 (a.i. chlorothalonil) per liter of water, applied at rate of 0.84 liter per plot (468 liter/ha) seven times in 1998 and five times in 1999.

${ }^{x}$ Values are means of four replicates, each with inoculum from a different field replicate.

${ }^{y}$ Within a year, underlined means followed by the same letter are not significantly different at $P \leq 0.05$ according to Fisher's least significant difference (LSD) test. In a separate comparison, 'W-301' and 'Stephens' means within a year followed by the same letter are not significantly different from each other $(P \leq 0.05)$.

${ }^{\mathrm{z}}$ Means followed by the same letter within a row are not significantly different at $P=0.05$ according to Fisher's protected LSD test.
Why did our results diverge from those of Ahmed et al. (1) even though the two studies occurred in the same geographic region, utilized similar methodology, and shared two cultivars (Madsen and Stephens) as sources of isolates and testers? For one thing, the larger of the two experiments conducted by Ahmed et al. (1) was not designed to estimate the selective effects of different levels of resistance on aggressiveness, because it included only one highly resistant cultivar (Gene), one moderately resistant cultivar (Madsen), and two susceptible cultivars (Stephens and Malcolm). The apparent association of cultivar susceptibility and isolate aggressiveness was not borne out when the moderate and low levels of resistance were replicated in the present study.

Moreover, Ahmed et al. (1) chose cultivars that were relevant to commercial production and, by chance, the two susceptible cultivars were very closely related to each other. The greater mean pathogenicity of isolate populations from cvs. Stephens and Malcolm was almost entirely due to the greater disease severity incited by those isolates on the same two cultivars. Because Stephens had been the dominant cultivar in the Willamette Valley for many years, greater pathogenicity in isolate populations derived from it and from its close relative cv. Malcolm may merely have reflected the long period available for specific adaptation to cv. Stephens. In fact, the analysis of variance performed by Ahmed et al. (1) revealed a significant pathogen population-tester cultivar interaction, which is indicative of specificity and clouds the interpretation of the significant main effect of pathogen population.

The difference in outcomes of the two studies may be partially attributable to pathogen population shifts in the interval between them. Ahmed et al. used isolates collected in 1992 and 1994, whereas the isolates for this work were collected in 1998 and 1999. In the intervening years, the dominant cultivar in the Willamette Valley shifted from susceptible cv. Stephens to moderately resistant cv. Madsen, and epidemic severity generally appeared to increase $(2,17)$. Additionally, cv. Gene's resistance, which was nearly complete at the time that isolates were collected from it for the earlier experiment (1992) but had deteriorated substantially just 3 years later, appears to have been specific (2). Examination of the data $(1,2)$ reveals that $\mathrm{cv}$. Gene had a different selective impact on aggressiveness before and after it selected for strains able to overcome its resistance.

Differences in aggressiveness were not significant in either year when comparing moderately resistant-derived populations to susceptible-derived populations as groups at the late collection date (Table 2), which was the criterion used by Ahmed et al. (1). However, there was some variability in aggressiveness among populations within those groups in the early collections (Table 2). There were also differences in cultivar resistance level within the moderately resistant and susceptible categories (Table 1). Averaging across the variability within moderately resistant and susceptible groups for pathogen population aggressiveness and for degree of host resistance obscured the selective effect of host resistance level. That selective effect became significant using linear regression of $A_{L}-A_{E}$ on disease severity so that individual host effects could be measured.

The interaction of isolate source with tester cultivar was nonsignificant in both years of this study. Other studies have found both significant $(1,2,7,12-14)$ and nonsignificant (25) interactions of M. graminicola isolates or isolate populations and tester cultivars within a particular wheat species. As Kema et al. (13) showed, some combinations of isolates and cultivars display high specificity, while other combinations possess low specificity. We have detected both qualitative (2) and quantitative (17) adaptation to hosts by $M$. graminicola. Although what we observed in the present study was probably selection for aggressiveness, the difficulty of distinguishing aggressiveness from virulence in this pathosystem should be remembered (11).

For 1998 isolate populations, we observed both modest evidence of adaptation to individual host genotypes and a mean de- 
cline in aggressiveness over the growing season. Neither of these effects was detected for the 1999 populations. The epidemic of 1998 was considerably more intense than that of 1999 , owing to the wet spring of the first year and the unusually dry late spring of the second year. It is reasonable to suppose that greater epidemic intensity might facilitate stronger selection. Why selection should have favored decreased, rather than increased, aggressiveness in 1998 is unclear.

Given the findings of Ahmed et al. (1), we designed the ratereduction experiment to help expose the mechanism by which susceptible cultivars might select for more aggressive isolates. That is, we expected that the lower rate of pathogen reproduction induced by the fungicide would result in isolates that were less aggressive than isolates from unsprayed plots of the same susceptible cultivars. In fact, we found the opposite, that isolates from the sprayed treatments were significantly more aggressive than isolates from the unsprayed treatments in both years of the experiment. This result is consistent with our finding that more resistant cultivars select for more aggressive isolates. The multisite fungicide and partial host resistance exercised qualitatively similar selective pressures on the fungal populations exposed to them. The influence of the fungicide was evidently more powerful than that of the resistance, because there were significant differences in aggressiveness of isolates from sprayed and unsprayed plots in both years but not of late isolates from moderately resistant and susceptible plots in either year.

In both years, cv. Lewjain was the most susceptible of the six tester cultivars (Table 2), although cv. Lewjain had the lowest disease severity both years in our field assessments (Table 1). In the same vein, cv. W-301 displayed high susceptibility in the field but low to intermediate susceptibility as a tester. One explanation for these inconsistencies may be that genes governing resistance to $M$. graminicola differ during juvenile and adult growth stages, as has been shown (14). Cultivar Lewjain matures 7 to 9 days later than most of the other cultivars in this study, so its adult resistance may be associated with its different growth habit. One would expect the $A_{L}-A_{E}$ measure of within-season selection for aggressiveness to be relatively robust to juvenile-adult plant resistance differences. Although the three susceptible testers and moderately resistant tester cv. Cashup expressed roughly consistent disease ranking both within and between years, cv. Madsen's performance as a tester was inconsistent between years in both experiments (Tables 2 and 4), and we are uncertain why. Theoretically, the presence of race-specific resistance genes could account for such anomalies as those observed with cvs. Lewjain, W-301, and Madsen. However, in both years the isolate source-tester interaction was nonsignificant and did not depend on collection date (Table 3).

In summary, earlier suggestions (1) (C. C. Mundt, unpublished data) that host susceptibility selects for increased pathogen aggressiveness may have been caused by artifacts in experiments that were not originally designed to test this hypothesis. Results of the present study suggest that disease management practices that suppress epidemic development (e.g., quantitative resistance and protectant fungicides) may select for increased pathogen aggressiveness, a result consistent with previous studies $(19,22)$. Conditions in the Willamette Valley of Oregon are highly favorable for adaptation of $M$. graminicola (17). Thus, similar effects may not be detected within a single season for pathogens that are less variable, in situations where epidemics are less frequent, or where there is significant pathogen migration from areas with different selective influences.

\section{ACKNOWLEDGMENTS}

This study was supported by award 97-35303-4537 of the NRI Competitive Grants Program/USDA. We thank D. Coyle, M. Hoffer, and $\mathrm{K}$. Webb for expert technical assistance; D. Thomas for statistical advice; and the anonymous reviewers for their comments, which considerably strengthened the paper.

\section{LITERATURE CITED}

1. Ahmed, H. U., Mundt, C. C., Hoffer, M. E., and Coakley, S. M. 1996. Selective influence of wheat cultivars on pathogenicity of Mycosphaerella graminicola (anamorph Septoria tritici). Phytopathology 86:454-458.

2. Cowger, C., Hoffer, M. E., and Mundt, C. C. 2000. Specific adaptation by Mycosphaerella graminicola to a resistant wheat cultivar. Plant Pathol. 49:445-451.

3. Cowger, C., Mundt, C. C., and Hoffer, M. E. 1999. A vertically resistant wheat cultivar selects for specifically adapted Mycosphaerella graminicola strains. Pages 85-86 in: Septoria and Stagonospora Diseases of Cereals: A Compilation of Global Research. M. van Ginkel, A. McNab, and J. Krupinsky, eds. CIMMYT, Mexico, D.F

4. Dubin, J., and Rajaram, S. 1996. Breeding disease-resistant wheats for tropical highlands and lowlands. Annu. Rev. Phytopathol. 34:503-526.

5. Eyal, Z. 1999. Breeding for resistance to Septoria and Stagonospora diseases of wheat. Pages 115-130 in: Septoria on Cereals: A Study of Pathosystems. J. A. Lucas, P. Bowyer, and A. M. Anderson, eds. CAB International, Wallingford, UK.

6. Eyal, Z. 1999. The Septoria tritici and Stagonospora nodorum blotch diseases of wheat. Eur. J. Plant Pathol. 7:629-641.

7. Eyal, Z., Amiri, Z., and Wahl, I. 1973. Physiologic specialization of Septoria tritici. Phytopathology 63:1087-1091.

8. Gandon, S., and Michalakis, Y. 2000. Evolution of parasite virulence against qualitative or quantitative host resistance. Proc. R. Soc. Lond. B 267:985-990.

9. Jlibene, M., and El Bouami, F. 1995. Inheritance of partial resistance to Septoria tritici in hexaploid wheat (Triticum aestivum). Pages 117-124 in: Proc. Septoria tritici Workshop. S. L. Gilchrist, M. van Ginkel, A. McNab, and G. M. J. Kema, eds. CIMMYT, Mexico, D.F.

10. Jlibene, M., Gustafson, J. P., and Rajaram, S. 1994. Inheritance of resistance to Mycosphaerella graminicola in hexaploid wheat. Plant Breed. 112:301-310.

11. Johnson, R. 1992. Past, present and future opportunities in breeding for disease resistance, with examples from wheat. Euphytica 63:3-22.

12. Kema, G. H. J., Annone, J. G., Sayoud, R., van Silfhout, C. H., Van Ginkel, M., and de Bree, J. 1996. Genetic variation for virulence and resistance in the wheat-Mycosphaerella graminicola pathosystem. I. Interactions between pathogen isolates and host cultivars. Phytopathology 86:200-212.

13. Kema, G. H. J., Sayoud, R., Annone, J. G., and Van Silfhout, C. H. 1996. Genetic variation for virulence and resistance in the wheat-Mycosphaerella graminicola pathosystem. II. Analysis of interactions between pathogen isolates and host cultivars. Phytopathology 86:213-220.

14. Kema, G. H. J., and van Silfhout, C. H. 1997. Genetic variation for virulence and resistance in the wheat-Mycosphaerella graminicola pathosystem. III. Comparative seedling and adult plant experiments. Phytopathology 87:266-272.

15. McDonald, B. A., Mundt, C. C., and Chen, R.-S. 1996. The role of selection on the genetic structure of pathogen populations: Evidence from field experiments with Mycosphaerella graminicola on wheat. Euphytica 92:73-80.

16. Milus, E. A., and Chalkley, D. B. 1997. Effect of previous crop, seedborne inoculum, and fungicides on development of Stagonospora blotch. Plant Dis. 81:1279-1283.

17. Mundt, C. C., Hoffer, M. E., Ahmed, H. U., Coakley, S. M., DiLeone, J. A., and Cowger, C. 1999. Population genetics and host resistance. Pages 115-130 in: Septoria on Cereals: A Study of Pathosystems. J. A. Lucas, P. Bowyer, and A. M. Anderson, eds. CAB International, Wallingford, UK.

18. Petersson, S., and Schnurer, J. 1999. Growth of Penicillium roqueforti, $P$. carneum, and $P$. paneum during malfunctioning airtight storage of highmoisture grain cultivars. Postharv. Biol. Technol. 1:47-54.

19. Pink, D. A. C., Lot, H., and Johnson, R. 1992. Novel pathotypes of lettuce mosaic virus-Breakdown of a durable resistance? Euphytica 63:169-174.

20. Rubiales, D., Reader, S. M., and Martin, A. 2000. Chromosomal location of resistance to Septoria tritici in Hordeum chilense determined by the study of chromosomal addition and substitution lines in 'Chinese Spring' wheat. Euphytica 3:221-224.

21. Scharen, A. L. 1999. Biology of the Septoria/Stagonospora pathogens: An overview. Pages 19-22 in: Septoria and Stagonospora Diseases of Cereals: A Compilation of Global Research. M. van Ginkel, A. McNab, and J. Krupinsky, eds. CIMMYT, Mexico, D.F.

22. Schouten, H. J., and Beniers, J. E. 1997. Durability of resistance to Globodera pallida. I. Changes in pathogenicity, virulence, and aggres- 
siveness during reproduction on partially resistant potato cultivars. Phytopathology 87:862-867.

23. Vanderplank, J. E. 1968. Disease Resistance in Plants. Academic Press, New York.

24. van Ginkel, M., and Rajaram, S. 1999. Breeding for resistance to the Septoria/Stagonospora blights of wheat. Pages 117-126 in: Septoria and Stagonospora Diseases of Cereals: A Compilation of Global Research.
M. van Ginkel, A. McNab, and J. Krupinsky, eds. CIMMYT, Mexico, D.F. 25. van Ginkel, M., and Scharen, A. L. 1988. Host-pathogen relationships of wheat and Septoria tritici. Phytopathology 78:762-766.

26. Zhan, J., Mundt, C. C., and McDonald, B. A. 2001. Using restriction fragment length polymorphisms to assess temporal variation and estimate the number of ascospores that initiate epidemics in field populations of Mycosphaerella graminicola. Phytopathology 91:1011-1017. 